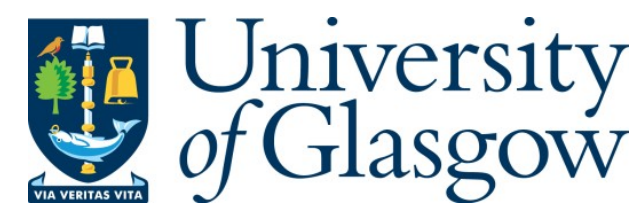

M artin-J ones, David (2014) Remembering the body: D eleuze's recollectionimage, and the spectacle of physical memory in Yip M an/lp

M an(2008). Journal of Chinese Cinemas, 8 (2). pp. 111-122. ISSN 17508061

Copyright $\odot 2014$ Taylor and Francis

A copy can be downloaded for personal non-commercial research or study, without prior permission or charge

Content must not be changed in any way or reproduced in any format or medium without the formal permission of the copyright holder(s)

When referring to this work, full bibliographic details must be given

http://eprints.gla.ac.uk/94139/

Deposited on: 23 J uly 2014

Enlighten - Research publications by members of the U niversity of Glasgow http://eprints.gla.ac.uk 


\section{Remembering the Body: Deleuze's recollection-image, and the spectacle of physical memory in Yip Man/lp Man (2008).}

David M artin-Jones

\section{KEYWORDS}

Ip M an, Deleuze, recollection-image, martial arts, physical memory, Chinese diaspora.

\section{ABSTRACT}

This article explores how Gilles Deleuze's conceptualization of the flashback, as 'recollection-image', can assist our understanding of the rendering spectacular of physical memory in contemporary Chinese martial arts movies. The focus is a prominent flashback in the climactic duel in the kung fu movie, Y ip M an/lp M an (Yip, 2008). This recollection-image demonstrates how trained bodies in Chinese martial art movies suggest a slightly different understanding of time and affect from that which D eleuze formulated, based on his observation of US and European films. On textual, cultural and historical levels this article explores the usefulness of martial arts movies for developing our understanding of physicality in cinema, and for reconsidering Deleuze's ideas in light of the Eurocentrism of some of his conclusions. 


\section{INTRODUCTION}

Gilles Deleuze's conceptualization of the flashback as 'recollection-image' (1985: 46), which I clarify below, can assist our understanding of the rendering spectacular of physical memory in contemporary Chinese martial arts movies. This is shown through analysis of a prominent flashback in the climactic duel in the kung fu movie, Yip Man/lp M an (Y ip, 2008), although a similar analysis could be applied to recollection-image flashbacks in such recent films as $\mathrm{H}$ uo Yuan J ia/F earless (Y u, 2006), Yip M an 2//p M an 2: Legend of the Grandmaster (Y ip, 2010), or the wuxia film, Jianyu/Reign of Assassins (Su, 2010).

I argue that Ip M an emphasises the maintenance of a specific type of identifiably Chinese heritage, through the recollection-image's spectacular depiction of physical memory, in a manner that potentially appeals to Chinese audiences worldwide. In addition, an examination of the aesthetic function of the recollection-image demonstrates how trained bodies in Chinese martial art movies suggest a slightly different understanding of time and affect from that which Deleuze formulated. This is uncovered through an observation of the spectacular nature of martial arts films, and the similarities between martial arts bodies onscreen and the performance tradition of Chinese opera. The way in which habit is conceived of by Chinese opera performers differs slightly from the Bergsonian conception of habit which underpins Deleuze's ideas. This allows a redefinition of the conclusions Deleuze draws from his analysis of European and US cinemas, through their encounter with the aesthetic and performance traditions influencing Chinese cinema. Thus on textual, cultural and historical levels this article explores the usefulness of martial arts movies for developing our understanding of physicality in cinema, and for reconsidering the Eurocentrism of Deleuze's conclusions, as they increasingly permeate mainstream film theory. 


\section{IP MAN}

Ip Man is a US\$12m M andarin Films production from Hong $\mathrm{K}$ ong. It is a kung fu film shot in the PRC (in Shanghai), clearly aiming at this larger market. It is one of several films about Y ip $M$ an in the 2000s/2010s, including Yip M an 2, Yip M an chinchyun/The Legend is Born: Ip Man (a.k.a Ip Man 3) (Y au, 2010), Yi dai zong shi/The Grandmaster (W ong, 2013) and Ip Man: The Final Fight (Y au, 2013).

Ip Man is set in Foshan, China, and opens in 1935. It focuses on the Wing Chun master $Y$ ip $M$ an (Donnie $Y$ en), al though it rather loosely retells his real life story. $Y$ ip $M$ an is introduced as a respectful martial arts master who does not take on pupils, preferring the privacy of his weal thy life. The film emphasises the importance of his training, especially his use of the wooden dummy which features in the credits, the very opening shot of the film, and intermittently thereafter. W hen the J apanese occupation arrives in 1937 (in Foshan in 1938), Y ip M an's mansion is confiscated by the Japanese army. $Y$ ip $M$ an works as a labourer to feed his family. The J apanese military offer Chinese martial artists the chance to fight Japanese soldiers in exchange for food. When fellow kung fu expert, M aster Liu (Chen Zhihui) is murdered by the J apanese military, $\mathrm{Y}$ ip $\mathrm{M}$ an severely beats numerous J apanese soldiers. Later, after defending his wife from impending rape, $Y$ ip $M$ an is captured and fights a public duel with the Japanese G eneral M iura (Hiroyuki Ikeuchi), which he wins. In the final moments of the duel, as $Y$ ip $M$ an beats $M$ iura to a pulp, a recollection-image flashback appears showing Y ip M an's previous training on his wooden dummy, the parallel montage that intercuts frequently between the past and present (the memory of training and the blows landing during the fight) demonstrating how his physical memory returns during the fight.

The film ends with a coda telling of Y ip M an's departure for Hong Kong in 1949 (the sequel is set in Hong $\mathrm{K}$ ong, and sees $\mathrm{Y}$ ip $\mathrm{M}$ an defeating the $\mathrm{B}$ ritish), where he became the teacher of 
Bruce Lee. No mention is made of the Civil W ar, the ending almost tacitly implying that $Y$ ip M an migrated as a consequence of the J apanese occupation, as opposed to the Civil W ar or communist rule.

The final fight scene provides a clear demonstration of how the affective nature of physical memory can influence the kind of image we experience in martial arts movies. The recollection-image flashback at the crucial moment in the duel introduces the memory of physical training in an elongated affective moment, temporarily suspending continuation and adding historical depth to the image. This return of physical memory is an accentuation of what we see in many martial arts movies, which chart a character's progress in mastering a particular fighting style. Of the countless examples, the recent remake of The K arate $\mathrm{K}$ id (Zwart, 2010), starring J ackie Chan, uses the learned memory of the repetitious hanging up of a jacket to demonstrate this process. In such films, the duel is the culmination of training, and in it we witness the result of the martial artist's physical progression. This dramatizes much the same process of recollection seen in Ip Man's flashback, regardless of whether a flashback is actually present or not. Y et on this occasion there is a flashback, one whose function Deleuze's theory can help us unlock.

\section{THE RECOLLECTION-IMAGE}

In Deleuze's taxonomy of images, the term recollection-image refers to the manifestation in image form of Henri B ergson's idea of attentive recollection. This is the process through which memories - which, for B ergson, exist virtually in a giant cone-shaped store of the past - are accessed in order to inform events in the present (M artin-J ones, 2006: 51-55). 
In the Cinema books, Deleuze, drawing on B ergson, argues that the universe exists as image, and people are but images amongst the universal flux of images. We all exist within the virtual and expanding whole of time, or Bergson's duration (Deleuze, 1983: 1-12 and 58-72; 1985: 42-65), in a form of creative evolution, or becoming. A ccordingly, cinematic images are not representations of reality, they are reality. Films show us how we relate to reality in two ways; through movement (movement-images) and through time (time-images). For this discussion the movement-image is key, because the recollection-image in Yip M an is of the kind found in this broader regime of images.

M ovement-images are chunks of space-time, actualised blocks of time in which virtual temporal possibilities are made actual through action. M ovement-images occur in three primary types, illustrating the sensory-motor continuity that they maintain. These are: perception-images (images of what is seen, such as point of view shots), affection-images (showing the affect of perception-images, for instance, close ups in which facial expressions magnify the micro reactions of the body to what is perceived), and action-images (images of sensory-motor actions taken as a result of perception and affection).

The recollection-image appears in the interval between perception and action, and, as seen in the conventional flashback, typically provides a brief moment of reverie before we return to the present and the resumption of sensory-motor continuity. Deleuze states that its typical function is to affirm the veracity of one true time, to maintain the sensory-motor logic of present actions (1985: 46). In movement-images, the recollection-image ultimately prolongs the sensory-motor continuity of the movement-image, to make action in the present continuous once again. For instance the recollection-image can fill in information that explains actions in the present, such as the motivation for revenge in C'era una volta il West/O nce U pon a Time in the West (L eone, 1968). In movement-image films a recollectionimage is best understood as a flashback in which an event in the past is recalled because it 
"matches" an event in the present, often through a sensory-motor similarity (e.g. in Sergio Leone's film, the sound of a harmonica to identify a character in past and present). It is a truth-affirming device, an image of recognition from the past that informs the present, and facilitates its continuation. A recollection-image informs sensory-motor continuity to enable bodily progression.

In Chinese martial arts films the recollection-image plays a very similar role to that found in the classical Hollywood and European films which Deleuze discusses, serving to elongate the moment of recognition and provide historical depth to the present. $Y$ et in $C$ hinese martial arts films a different attitude emerges towards the body's existence in, and physical recollection of, time. These films can use the recollection-image slightly differently, to show the affective experience of learned physical memory, when martial arts training re-appears during a fight. The typically spectacular nature of the Chinese martial arts flashback elongates time during the duel, in the interval between perception and action. This functions in tandem with the affective cinematography and montage of the fight scene, and a distinctive style of bodily performance on the part of the martial artist expressive of a trained physique which recalls the past physically.

\section{THE DUEL: RECOLLECTION-IMAGE, AFFECTION-IMAGE.}

In Ip M an, the duel is marked by much slow motion cinematography emphasising the flight of bodies through the air, high kicks, and when strikes land with full force. This elongates the temporal moment of the duel, and simultaneously renders it spectacular. The context this provides, of time becoming suspended in the present, provides the perfect conditions for the past to intercede through the recollection-image. It appears as $Y$ ip $M$ an pins $M$ uira to the post in the corner of the ring, and he beats him to a defeated sitting position. The juxtaposition 
between past and present that occurs al most renders $M$ uira invisible, as the post in the present matches the frame of the wooden practice dummy in the past.

The affective nature of this return of the past is evident in Y ip M an's facial expressions. In the flashback, Y ip M an's face in the past is entirely placid, his eyes often closed as he trains, his movements ever more fluid as a result. In the duel, after the flashback appears and $Y$ ip $\mathrm{M}$ an is victorious, the camera comes to rest on his face in the present: an affection-image. Donnie Y en's facial expression shifts from a focused determination which looks through his opponent, to recognition (tempered with compassion) that he has been fighting a living person. $Y$ en's face then returns to $Y$ ip M an's characteristic humility.

This change of expression is noticeable because throughout the duel $Y$ ip $M$ an's face remains fairly calm, even if not as placid as in the flashback. The juxtaposition between past and present ensures that his fighting moves seem almost as automatic as those practised in the past. This is in keeping with his cool fighting style until this point in the movie, as $Y$ en performs Y ip M an as supremely in control of his actions and emotions with only a determinedly furrowed brow and an apparent tension in his shoulders to display occasional anger. Even when Y ip M an brutally dispatches multiple nameless J apanese soldiers there is no sign of such depth of emotion that a flashback to his physical training is warranted. $Y$ et in the closing duel, as $Y$ ip $M$ an repeats actions perfected during training, the recollection-image visualises the return of physical memories of this shaping of the body. A fter the recollectionimage, $Y$ ip $M$ an's face is noticeably expressive, indicating the affective return of his physical memory, which flow through his body with full force. In this affection-image, his expression shifts from detached fury to recognition of an actual foe, as he glances down to M uira's bloodied face. In this way, in line with his previous, seemingly "automatic" fighting style, the violence of his actions are rendered as the return in the present of physical habits acquired in the past. $\mathrm{His}$ body is a conduit through which the past flows due to the match between his 
actions then and now, the gateway through which - after B ergson - stored virtual memories have re-emerged. For this reason his expression shifts from neutral to a shocked recognition of the devastation caused to his opponent. Y en's face, the blank expression of a fighting machine, registers his seeming absence during the fight as his body simply expresses the return of stored physical memories.

Thus the insertion of a recollection-image during the duel enables the audience to experience this affective return of the past. It pays homage to the tradition of physical training that the martial artist has undergone, both the venerated character of Ip $\mathrm{M}$ an who is the subject of the film (the man who trained Bruce Lee), and the martial arts star, Y en.

\section{REMEMBERING CHINA: MOBILIZATION AND HERITAGE}

B efore I turn to explore how distinct this recollection-image is from those in W estern cinemas, and how this requires a reconsideration of Deleuze's conclusions, it is necessary to first explore why Yip Man depicts physical memory in this way.

W ith its foregrounded nationalism, Ip M an clearly has designs on pan-Chinese if not panA sian audiences. M ost importantly, Ip M an emerges in the context of efforts made by A sian filmmakers to cultivate the potentially lucrative market of mainland Chinese viewers. This typically necessitates a negotiation of the pitfalls of censorship, party politics and profit motivations, which requires a co-production arrangement with a Chinese company (Davis and Y eh 2008: 29-37 and 106-110). A ccordingly, Ip Man's PRC production associates include - along with Time A ntaeus M edia, B eijing ShengShi HuaR ei Film Investment and M anagement, and Beijing N ew Film A ssociation - the China Film Co-Production Corporation. This subsidiary of China Film Group Corporation has both the exclusive 
'official mandate' to act as agent for international coproductions and as 'watchdog', in 'censoring scripts and screening applications, and assigning suitable domestic studios for line production' (Y eh \& Davis, 2008: 46). Ip Man is thus not untypical of the coproductions between Hong $\mathrm{K}$ ong and the mainland to proliferate since the establishing of the Common Economic Partnership A rrangement, in 2003, enabling Hong K ong productions with sufficient mainland participation to count as domestic Chinese rel eases, therefore circumventing the PRC's quota on imported films. (Y eh \& Davis, 2008: 45; B erry, 2010: 118)

A ttempting to appeal to Chinese audiences globally is not a new practice. Poshek Fu details how the Shaw Brothers in the 1960s attempted to produce a diasporic consciousness, through nostalgic, often mythical depictions of the national past and the focus on shared (if perhaps invented) cultural traditions (Fu 2008: 6). N owadays, a similar point has been made about Ang Lee's wuxia blockbuster Crouching Tiger, Hidden Dragon (2000) (Chan 2004; K lein 2004). The situation in which Ip M an was produced is a result of changes since the 1980 s, such as, modernization of the PRC, the handover of Hong K ong, the end of martial law in Taiwan, the 'high-tech liberalization' of Singapore, and the regional rise of cosmopolitan youth consumer cultures (Curtin 2007: 3). In this context, David Desser finds a concerted effort being made by contemporary Chinese filmmakers to express 'cultural nationalism' through the martial arts movie, in particular in blockbusters in the wake of Ying Xiong /H ero (Zhang 2002) which use 'Chinese history to work through the new reality of China as an emergent power on the world scene.' (2011: 2) Of the companies associated with the production of Ip M an, the Shanghai Film Group and the China Film Group Corporation are amongst those known for their use of ' commercial funding between Chinese-language markets ... to expand and consolidate ethnic Chinese audiences A sia-wide.' (Davis and Y eh 2008: 90) Thus it is not paradoxical that a nationalistic storyline appealing to mainland 
audiences (Ip M an 2 earned US\$15m in its first week in China (Paquet 2010: 48)) is also used to reach pan-A sian audiences (I p M an 2 also performed well in Hong Kong, M alaysia, Singapore and $\operatorname{Taiwan}^{1}$ ). In light of this industrial context, the recollection-image can be considered a device which explores China's cultural heritage (here, the martial arts tradition) as a stored, physical memory, so as to appeal to audiences who constitute an "ethnic" nationalist Chinese community, both in China, and the global diaspora.

Research into the proximate film industry of South $\mathrm{K}$ orea has resonances for Ip M an in this respect. Chris Howard writes of the recent success of the South K orean film industry in 'mobilising' domestic viewers towards the 'patriotic' consumption' of South K orean cinema, using nationalism (specifically relating the consumption of South K orean films to the notion of minjok, 'one blood ethnic nationhood') in order to secure the distribution of the content of the nation's creative industries (2008: 88-102). We might add to this popular Indian (Bollywood) cinema's global propagation of an ideological value system which is associable with that of the middle classes, to sell movies to the diasporic market whilst consolidating a specific hegemonic value system (Dwyer 2000). The latter of these, the ideological aspect, is key to the success of the former, economic aim, in ensuring the "identity" of the target market is not eroded through contamination by contact with other cultures and value systems. Ip Man, then, is not solely involved in a process of cultivating a pan-A sian audience. Like its South K orean counterparts it is also mobilising a form of (in this case, Chinese) ethnic nationalism. In this process it uses the recollection-image to focus on the return of a stored physical memory of a practice heavily associated with cultural heritage. M oreover, like its Indian counterparts, Ip M an reaches out beyond the nation to consolidate Chinese-language audiences generally. This is evident in the film's webpage, which states: 'This movie will see the making of a modern wushu master representative of Chinese people worldwide. ${ }^{2}$ W hat is interesting for this discussion of the recollection-image is that the film expresses the need to 
retain this type of cultural heritage, to ensure the prolongation of ethnic notions of nationhood, physically.

The notion that cultural heritage is maintained in the body of the martial artist - that the physique is a conduit through which a stored memory, accumulated through physical training, flows - resonates beyond cinema. In an anthropological study of martial arts in the Chinese diaspora, D.S. Farrer discusses how kung fu functions as an 'embodied social memory' (2011: 207):

A ctive remembering produces martial arts culture at its richest and makes for remembrance that is simultaneously enacted and immanent. Like an external memory, the overseas Chinese martial arts exist as a vast reservoir of Chinese cultural capital, one that has the potential to be reinvested back into China. (228)

Similarly, Ip M an, a Hong K ong film with the mainland in its sites, attempts to return stored physical memories to an audience who, for historical reasons (especially the reorganisation of martial arts by the Communist Party after the Civil W ar), have to some extent lost touch with these physical memories. In related research, Gina M archetti finds that films like the recent The Karate Kid remake celebrate 'diasporic contacts' and 'call for China to ... recognise other uses of Chinese tradition.' (2012: 199) In a similar vein, Ip M an reminds (or perhaps more accurately in some instances, informs) audiences in the PRC of a Chinese heritage (both martial arts and the martial arts movie) available in Hong K ong and beyond, which bypassed many during the Cultural Revolution. Hong Kong cinema, after all, has long preserved a martial arts heritage that is healthy in the diaspora (evident in Donnie Y en's training in Hong K ong and the USA ), and the recollection-image is used to help the mainland "remember" (whether this enables an actual memory, or a prosthetic one (Landsberg 2003)), how to experience the embodied memory of this tradition. 
In Ip Man the recollection-image taps the 'reservoir of Chinese cultural capital', to demonstrate the remembrance of a stored cultural heritage immanent to Chinese identity, and actual ised in its enactment. Y en's background as a martial artist trained outside of the PRC ensures that this is a return of a diasporic memory of this cultural tradition, kept alive in diasporic bodies. Indeed, Y en studied Wing Chun in preparation for the film with Ip M an's eldest son, Ip Chun, who has been based in Hong K ong since 1962. Thus the film reinvests Chinese audiences with this cultural capital through the affective rendering of the return of physical memories. In this way cultural nationalism can be propagated transnationally, both cultivating and perpetuating its own pan-A sian target market.

Here the distinction between Yip M an and The Karate Kid comes into focus. As M archetti notes, The Karate Kid's exploration of 'diasporic contacts' suggests that China should 'Ioosen up' in 'favor of more spontaneity, personal freedom, individuality, multiculturalism, and "traditional" Chinese values of harmony.' (199) Ip Man, by contrast, portrays the return of traditions kept alive in the diaspora as beneficial in terms of a nationalism which pitches Chinese against J apanese ethnicities and cultures.

The affective nature of this process of recollection is coded as one of national pride, in which a great deal is simultaneously "forgotten". Whilst I p Man is set during the J apanese occupation, the return of a martial arts heritage offsets any sense of shame - or other negative affect - associated with it. Even Li Chiu (K a Tung Lam) the former policeman and now interpreter, whose national loyalty appears ambiguous due to his collaboration with the J apanese, is recuperated when his motivation is revealed to be his need to support his family. Ip M an's physical training is what is remembered during the final duel, then, rather than the (ultimately, "forgotten") death of M aster Liu at the hands of the J apanese military. In this way a national history of occupation is turned into victory through the recollection-image, history being realigned accordingly with the arrival of a new informing memory. Ip $M$ an's is 
a body trained in a cultural heritage which was preserved in the face of colonial invasion, the film and its remake reassures us, by Japan and B ritain respectively. The historical role of the Nationalist Government and the Communist Party in banning martial arts movies, and controlling the practice of martial arts on the mainland is avoided al together (another aspect of history entirely "forgotten"). W hat is recollected, instead, promotes a cultural nationalism designed to appeal to mainland audiences and territories like Hong K ong, Tai wan and Singapore, as well as the diaspora globally.

\section{HABIT IN THE DUEL: QUICK DRAW VS REMEMBERED FIST}

W ith the role of the recollection-image established, I turn to the implications of its use in Chinese martial arts films for a constructive reconsideration of Deleuze. In Yip M an the physical performance of the martial artist renders time slightly differently to classical Hollywood movement-images. This is because the spectacular performance of the martial artist, like that of the Chinese opera performer, is based on a different view of habit from the Bergsonian conception which underpins Deleuze's work.

Bergson's notion of habit plays an important role in Deleuze's thinking about cinema. For both, habit is a form of memory distinct from attentive recollection, but one on which the recollection-image is based and therefore related to its functioning. In contrast to attentive recollection, in which a gap emerges between perception and action into which memories from the past can flow (the recollection-image as flashback), habit maintains sensory-motor continuity in the present by keeping the gap closed. Habit is the storing of physical memories through repetition such that they can be repeated later without the need for memory to intervene. Habit works by not allowing for the intervention of the past into the present during the moment when perception turns to action. In habit, the sensory-motor link between 
perception and action is so strong it suppresses the past. Accordingly, action is uninterrupted by flashbacks.

This conception of habit underpins Deleuze's thinking with regard to the role of the duel, in particular in relation to the western in Cinema 1. For Deleuze, in the classical Hollywood western the duel is the process through which the character, acting upon perception, is able to influence the broader (often, nationally representative) situation they find themselves in (1983: 31). W ith this in mind we can explore the differences between the appearance of the recollection-image in the contemporary martial arts duel (attentive recollection) and habit in the classical western, in terms of the different kinds of physical memories involved. The most obvious difference between the two is the amount of physical exertion required, and the need for a connection with a physical memory of the past experienced through the body. This informs the way time and movement are elongated in the martial arts duel. This is not to say that the physical experience of a quick draw is any different from that of a punch. Both draw and punch require the same return of physical trained movements in a lightning fast manner produced by repetitious training. The point of such a stored physical memory, after all, is its enabling of recall without the intervention of conscious thought. Indeed, both instances involve selective processes of recollection and forgetting, both physical and historical. What is different is the manner in which the two are depicted.

In the classical US western, the gunslinger is typically depicted as having mythical or godlike speed. The origins of this speed in training are rarely shown, or at least not in the manner in which physical training is emphasised in martial arts films. Gunslingers are often men with no past, whose lightning fast draw enables the conquering of a supposedly virgin land, the USA of the myth of manifest destiny. The superhero in the classical Hollywood western is 
able to close the gap between perception and action to the extent that the past remains silent, much as the myth of manifest destiny erases the pre-Columbian histories of the colonised lands from which the native inhabitants were forcibly removed (M artin-J ones 2006: 121-127; 2011: 1-65).

At this very general level, then, a Deleuzian-informed comparison between the classical US western and the contemporary martial arts film illuminates how, by making a spectacle of attentive recollection, martial arts films place a greater visual emphasis on gaining access to the past. Whilst both are involved in selectively recollecting the past, unlike classical Hollywood westerns, martial arts films elongate time by emphasising the affective return of physical training in attentive recollection. This spectacle expresses the process through which habits are formed, and then recalled physically in the moment of performance. The spectacle we see is the body recalling this training process during the moment of performance. It operates on several levels simultaneously as character, martial artist, and film star all express their temporal debt to the training which enables them to perform the same learned habits. In the case of Yip M an, the process of recollecting (a certain take on) national history through the recollection-image is also a stark contrast with the eradication of the (indigenous) past found in the culminating duel of the classical US western.

Leaving aside momentarily the difficulties with such a generalisation, the importance of the correlation between the martial arts film and Chinese opera now becomes evident. ${ }^{3}$ In China on Screen (2006), Chris Berry and M ary Farquhar argue that operatic modes permeate martial art films and various other genres. They observe that 'shadow opera is ... the living core of a distinctive Chinese cinema' (47-48), and that an operatic mode has enabled Chinese cinema to appropriate this W estern media in a culturally national ist manner. Charting the 
convergence of film and opera from the silent period onwards, Berry and Farquhar note the spectacular nature of the mode ('an operatic aesthetic that choreographs performance as spectacle' (54)), which 'hails viewers first and foremost as Chinese people seeing a Chinese spectacle.' (48)

Further depth can be added to this argument by considering the role of the physical body of the performer in this spectacle. For instance, $Y$ ung Sai-shing notes the importance of the spectacle of the trained physical performer in Chinese opera:

Chinese opera is an actor-oriented theatre. The theatregoers' focus is concentrated on the actors' performing skills, constituted by their singing, reciting, body movement, and choreographic and acrobatic actions. ... The aesthetic focus of the audience concentrates on the performing artistry exhibited by an individual actor. To an initiated audience, an actor's skill and competence (including choreographic actions and martial/acrobatic arts) are the focal objects to be viewed and appreciated. The theme, characterization and plot development of the play might not be their main concerns. (2005: 28-29)

$Y$ ung argues that 'the principle of highlighting the action/body of the actors', found in Chinese opera, has been transferred to 'contemporary action cinema', ensuring that 'the body of an actor has become the spectacle.' (29) A s is evidenced in the films of J ackie Chan, an action star famously trained in Chinese opera, in Chinese theatrical and cinematic traditions bodies are rendered slightly differently for cultural reasons (M artin-J ones, 2011, 133-161). This gives us cause to reconsider the role of the underlying philosophical explanation from B ergson, especially his emphasis on habit, in constructing Deleuze's image types. 
Duels in the martial arts film demonstrate a montage designed to emphasise attentive recollection as spectacle. These are movies in which the memory of physical training is paramount to the success of the fighter in the duel. The recollection-image is used to heighten affect and to elongate the action to the point where time intercedes in the interval, rendering spectacular the physical training that has gone into the performance of the body.

Chinese opera does something similar, showing off a spectacle of the accomplished actor through movements which have taken years of training to execute. In this process of training, if we follow Li Ruru in The Soul of Beijing Opera (2010), the opera actor learns to perform everyday movements in a stylised manner. Through this habit they learn to perform a different self. Li states of the use of the word 'habit' by opera stars in their discussions of their training, that: 'The "habit" used by jingju professionals in fact refers to a process of transformation, from a "personal I" to a "performer I".' (72) Whilst we could try to see this divided I as synonymous with Bergson's notion of the subject dividing in time (a present self that passes (the performance) and a past self that is preserved (the performer)), this does not entirely hold true for this example. There is a different understanding of habit at work in the two instances, suggesting that Deleuze's work on cinema requires some refinement in the case of martial arts cinema.

As noted above, for B ergson, habit closes off the body to the intrusion of time. By maintaining an unbroken sensory-motor schema, habit retains the illusion of a continuous, singular sense of self in the present. A ccordingly, for Deleuze, the gunslinger in the western experiences no pause between perception and action. In Chinese opera and martial arts films, however, we are treated to the spectacle of the result of this habit, in the elongated moment in 
which we witness both performer and performance co-existing. The moment in which the self divides is experienced as spectacle, and prolonged, prior to its return to action. Rather than amazingly quick, time becomes amazingly slow, as we witness the process of physical training which informs the ability of the performer to move in a stylised manner.

Thus, in martial arts cinema, as in Chinese opera, the divided nature of the self is revealed through performance, and in these standout moments physical habit is deployed as spectacle. Here the recollection-image serves not to explain the root cause of the present actions (this is not a flashback to give the reason for a revenge killing) but to enable us to experience the self, divided in time, as constructed by habit-forming physical training. The Chinese martial arts film reveals a process of self-discipline through training in which habit leads not to a continuous, singular 'I' (an unbroken sensory-motor continuum of perception, affection, action), but rather to a split or divided 'I', of perfomer and performance.

It might be objected that much the same argument could be made for post-classical westerns, especially those after directors like Leone or Sam Peckinpah critiqued the classical US western formally and ideologically, in particular by revising the classical US western's notion of national history. Such affective moments are evident, for instance, in the slow motion duels and deaths in Peckinpah. Indeed, in Deleuze's work such films point to the challenges that face any definition of the movement-image (1983: 164-220), as is further evident in the nonconformity of contemporary martial arts films to the precise letter of Deleuze's definition. This objection, however, is part of a larger question of how we can understand the role of the recollection-image in martial arts films in relation to Deleuze's overall taxonomy. To address this I conclude by considering where Chinese martial arts films might "fit" in the Cinema books. 


\section{CHINESE OR TRANSNATIONAL MARTIAL ARTS MONTAGE?}

It is tempting to consider Chinese martial arts films to provide another form of movementimage to those identified in Cinema 1, based on the four types of montage Deleuze discusses - US, Soviet, French and German cinemas - primarily in the 1920 s and 1930s. We might consider this use of the recollection-image to suggest a "Chinese" form of montage, especially considering J ubin Hu's position that the martial arts film movement of the $1920 \mathrm{~s}$ was integral to the establishing of the national film industry (2003: 47-74), and Zhang Zhen's (2005) conception of the martial arts movement of the 1920 s as a form of vernacular modernism. Indeed, the case has been made by Chen M o (quoted by Stephen Teo (2009: 24)) that the first ever Chinese film (1905) was a martial arts movie, a rendering of Chinese opera moves in silent cinematic format. This, even though martial arts movies were banned in 1931 (Zhen 2005: 200; Davis and Y eh 2008: 127). How ever, there are two reasons why martial arts films are not simply evidence of a "Chinese montage".

Firstly, contemporary films like Ip M an are a product of historically shifting aesthetic pattern. Consider the development of "new school wuxia" (sometimes referred to as the "new wuxia century") by the Shaw Bros in Hong Kong in the 1960s (Law 2003; Teo 2009: 86-114), and the transformation of kung fu films - in the wake of Long hu dou/The Chinese Boxer (Wang, 1970), epitomised by Bruce Lee movies of the early 1970s - to emphasise the physicality of the fight through editing and cinematography (Teo 2009: 75 and 79). This coincided with a trend which emerged in the 1970s towards kung fu films emphasising physical training (e.g. the Jet Li Shaolin Temple films of the 1980s). At this time there was much cross-fertilization 
from J ames B ond films, E uropean spaghetti westerns and J apanese chanbara (jidai geki) samurai films on the new wuxia century (B ordwell 2000: 206; Law 2003; Teo 2009: 129). Since then there has been further cross-fertilization between Chinese and US action movies, for instance with action choreographer Y uen W o-ping - the son of a Chinese opera star (Y ung 2005: 24-25) - choreographing films like The Matrix (W achowski and W achowski, 1999). Historically, then, kung fu films embrace transnational influences to stay competitive, both domestically and abroad (Law 2003; Teo 2009: 86-114; Lee 2009: 119-123).

Therefore, to insert an additional pre-war montage into Deleuze's taxonomy we would need to consider the martial arts movies prior to the 1960s and 1970s, which more clearly demonstrated their origins in Chinese opera. $Y$ et the amount of editing in the duel in Ip Man was not typical of Chinese films prior to the Second W orld W ar. The influence of Chinese opera created a stage bound aesthetic, with long takes and little editing, to emphasise the skills of the fighters (Teo 2009: 72). In Hong Kong in the 1960s and 1970s there was a concerted move to break with the "stagy" feel of previous wuxia films, to emphasise the fighting, and reduce the fantasy and myth (Law 2003; Teo 2009: 130-134), in such films as King Hu's Da zui xia/C ome D rink With Me (1966) and Zhang Che's D ubei dao/O ne Armed Swordsman (1967). David Bordwell argues that this increased the amount of editing disguised special effects like wirework, whilst new technologies like widescreen and handheld cameras al so impacted on the new, seemingly more "realistic" aesthetic (2000: 206). Noticeably, this historical moment marked a move from opera films to martial arts movies in terms of popularity with Chinese audiences. But it was still influenced by Chinese opera. For example, King Hu notes the importance of the B eijing opera star Han Y ingjie for the choreography of the action scenes in Come D rink With Me and Xia nu/A Touch of Zen (1971) (Berry and Farquhar 2006: 53). So, whilst still demonstrating a definably Chinese 
influence on the aesthetic, this montage is a fairly recent phenomenon. A ccordingly we cannot add a "Chinese montage" category to D eleuze's list of national exemplars.

Secondly, it is difficult to discuss a national cinema in a Chinese context with three competing film industries (PRC, Hong K ong, Taiwan) and overlapping histories of representing China (Berry 2003: 2). To suggest that these Hong Kong films are "national" in the way that Deleuze does of the four European montage styles would be inappropriate. Even if we follow the thrust of B erry and Farquhar's research, which demonstrates how an operatic mode is prevalent in Chinese cinema across its history, such a category as "Chinese montage" would be over general in terms of the diversity of Chinese cinemas.

Instead, in Chinese films like Ip M an we see a form of montage that relates to trained bodies. This is less a "Chinese montage" than it is a "martial arts montage" which Chinese cinemas enable us to realise for cultural and historical reasons. Due to the influence of operatic and martial arts traditions, in Ip Man the recollection-image provides a meta-commentary on performance, revealing how martial arts develop physical habits in a similar manner to that of the Chinese operatic performance tradition (Li 2010: 71-72). The return of the past in the film's closing flashback has ramifications for its attempts to promote a continuation of Chinese heritage through its martial arts traditions. Although we can uncover this via engagement with D eleuze, ultimately this poses a challenge to his conclusions, as it is a different way of considering the past as a physical memory from that which Deleuze drew from Bergson. 


\section{ACKNOWLEDGEMENTS}

Thanks to everyone who gave feedback at the U niversities of Nottingham at Ningbo, Kaifeng, and Hong K ong. Especially: Gina M archetti, John B erra, Gary N eedham, David Fleming, Y un-hua Chen, Patricia Pisters, Ji-Y oung L ee, Clifton Evers, Grant Hamilton, Timothy O'Leary, Teresa Rizzo, M airéad Phillips, Lia W en-Ching Liang, Hanping Chiu, Y uLing Lee, H sien-Hao Sebastian Liao, W ong K in Y uen, J ohn M arks, Iain M ackenzie, R obert Porter.

\section{WORKS CITED}

B erry, Chris. 2003. 'One Film at a Time', in Chris B erry (ed.), Chinese Films in F ocus. London: BFI, pp. 1-5.

B erry, Chris and M ary Farquhar, 2006. China on Screen. N ew Y ork: Columbia U niversity Press.

B erry, Chris. 2010. 'W hat is transnational cinema?' Transnational Cinemas. 1: 2, pp. 111127.

Bordwell, David. 2000. Planet Hong K ong. Harvard: Harvard U niversity Press.

Chan, Kenneth. 2004. 'The Global Return of the Wu Xia Pian', Cinema J ournal. 43: 4, pp. 317.

Curtin, M ichael. 2007. Playing to the World's Biggest Audience. B erkeley: University of California Press. 
Davis, Darrell William and Y eh, Emilie Y ueh-yu. 2008. East Asian Screen Industries. London: B ritish Film Institute.

Deleuze, Gilles. [1983] 2005. Cinema 1: The M ovement-Image. trans. Hugh Tomlinson \& Barbara Habberjam, London: Continuum.

-- [1985] 2005. Cinema 2: The Time-Image. trans. Hugh Tomlinson \& R obert Galeta, London: Continuum.

Desser, D avid. 2011. 'Reclaiming a Legacy', in Kinnia Shuk-ting Y au (ed.), East Asian Cinema and Cultural Heritage. New Y ork: Palgrave M acmillan, pp. 1-25.

Dwyer, Rachel. 2000. All You Want is M oney, All You Need is Love. London: Cassell.

Farrer, D.S. 2011. 'Coffee-shop Gods', in D.S. Farrer and J ohn W halen-B ridge (eds.), Martial Arts as Embodied Knowledge A lbany: State University of N ew Y ork Press, pp. 203237.

Fu, Poshek. 2008. 'Introduction', in Poshek Fu (ed.), China F orever. U rbana and Chicago: University of Illinois Press, pp. 1-26.

Howard, Chris. 2008. 'Contemporary South Korean Cinema', in Leon Hunt \& Leung WingFai (eds.), East Asian Cinemas. London: I.B. Tauris.

Hu, Jubin. 2003. Projecting a Nation. Hong K ong: Hong K ong U niversity Press.

K lein, Christina. 2004. 'Crouching Tiger, Hidden Dragon'. Cinema J ournal. 43: 4, pp. 18-42.

Landsberg, A lison. 2003. 'Prosthetic memory', Paul Grainge (ed.), M emory and Popular F ilm. M anchester: M anchester University Press, pp. 144-161. 
Law, Kar. 2003. 'The Origin and Development of Shaws' Colour Wuxia Century' in W ong A in-Ling (ed.), The Shaw Screen. Hong K ong: Hong K ong Film A rchive, pp. 129-142.

Lee, Vivian P. Y. 2009. Hong Kong Cinema Since 1997. London: W allflower.

Li, Ruru. 2010. The Soul of Beijing O pera. Hong K ong: Hong Kong U niversity Press.

Louie, Kam. 2002. Theorising Chinese M asculinity. Cambridge: Cambridge University Press.

M archetti, Gina. 2012. The Chinese Diaspora on American Screens. Philadel phia: Temple University Press.

M artin-J ones, David. 2006. D eleuze, Cinema and National Identity. Edinburgh: Edinburgh University Press.

-- 2011. D eleuze and World Cinemas. London: Continuum.

Paquet, Darcy. 2010. 'Ip M an 2', Screen International. 1724, p. 48.

Teo, Stephen. 2009. Chinese Martial Arts Cinema. Edinburgh: Edinburgh University Press.

Y eh, Emilie Y euh-yu and Darrell W illiam Davis. 2008. 'Re-nationalising China's film industry' . J ournal of Chinese Cinemas. 2: 1, pp. 37-51.

Y ung, Sai-shing. 2005. 'M oving B ody', in M eaghan M orris, Siu Leung Li \& Stephen Chan

Ching-ku (eds), H ong Kong Connections. Hong K ong: Hong K ong U niversity Press, pp. 2134.

Zhen, Zhang. 2005. An Amorous H istory of the Silver Screen. Chicago: U niversity of Chicago Press. 
${ }^{1}$ B ased on B ox Office figures listed on B ox Office M ojo:

http://boxofficemojo.com/movies/?page=intl\&id=ipman2.htm (A ccessed 14/07/12).

${ }^{2}$ http://www.ipman-movie.com/main en.html (A ccessed 13/07/12)

${ }^{3}$ This discussion of the body in Chinese opera focuses specifically on the wu stratum of the wen and wu roles. For a full discussion of how this distinction impacts on cinematic roles, see K am Louie's Theorising Chinese M asculinity (whose discussion of wu masculinity in Bruce Lee, J ackie Chan and Chow Y un Fat (2002: 140-159) gestures towards Donnie Y en's performance in I $\mathrm{M}$ an), and again Berry and Farquhar (2006: 135-168). 